\title{
FTIR and Thermogravimetric Analysis of Three Kinds of Nutshells
}

\author{
Jinping Zhang, Yue Ying, Xuebin Li, Xiaohua Yao \\ Research Institute of Subtropical Forestry, Chinese Academy of Forestry, Hangzhou, China \\ Email: jinpingzhang@126.com
}

How to cite this paper: Zhang, J.P., Ying, Y., Li, X.B. and Yao, X.H. (2018) FTIR and Thermogravimetric Analysis of Three Kinds of Nutshells. Natural Resources, 9, 313-325. https://doi.org/10.4236/nr.2018.98019

Received: July 31, 2018

Accepted: August 25, 2018

Published: August 28, 2018

Copyright $\odot 2018$ by authors and Scientific Research Publishing Inc. This work is licensed under the Creative Commons Attribution International License (CC BY 4.0).

http://creativecommons.org/licenses/by/4.0/

\begin{abstract}
The main components and pyrolysis characteristics of Camellia oleifera Abel hells, Castanea mollissima Blume shells, and Castanea mollissima Blume shells were analyzed by using FTIR and thermogravimetric methods. The experimental results indicated that the main components of the three kinds of raw materials consisted of cellulose, hemicellulose, and lignin. The highest contents of hemicellulose, cellulose, and lignin were in Camellia oleifera Abel shells $(49.34 \% \pm 0.07 \%)$, Castanea mollissima Blume shells $(27.34 \% \pm 0.01 \%)$, and Carya cathayensis Sarg shells $(49.78 \% \pm 0.01 \%)$, respectively. The pyrolysis processes of three kinds of shells generally included three stages, namely dehydration, pyrolysis, and carbonization. The peak values and the appearance times of their pyrolysis rates were closely related to their compositions.
\end{abstract}

\section{Keywords}

Camellia oleifera Abel Shells, Castanea mollissima Blume Shells, Carya cathayensis Sarg Shells, FTIR, Thermogravimetric Analysis, Matrix Application

\section{Introduction}

China is a major producer of Camellia oleifera Abel (Figure 1(a)), Castanea mollissima Blume (Figure 1(b)), and hickory Carya cathayensis Sarg (Figure $1(\mathrm{c})$ ). Shells are the major by-products of these three fruits processing, and the weights of Castanea mollissima Blume shells and Camellia oleifera Abel shells account for more than $60 \%$ of their fresh fruits [1] [2], and the weight of Carya cathayensis Sarg shells is also more than $30 \%$ of its weight of fresh fruit [3]. According to the data issued by the ministry of agriculture of the People's Republic of China, annual production of Camellia oleifera Abel of China is nearly 8 million tons, the production of Castanea mollissima Blume is more than 1.7 million 


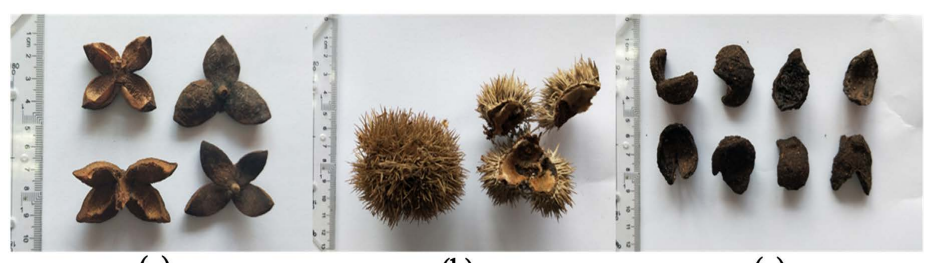

(a)

(b)

(c)

Figure 1. View of three kinds of nutshells.

tons and the production of Castanea mollissima Blume is nearly 900 thousands tons in China [4]. Therefore, tons of shells are produced every year. According to the previous studies, in addition to rich in organics, such as polysaccharide, tannin, and saponins, the total contents of cellulose, hemicellulose, and lignin in these shells exceed $80 \%$ the weights of their fresh fruits [5] [6], which endows the shells resources with great potentials. However, due to various issues such as difficulty in lignin degradation [7] or incomplete recycle technology, the shells are not utilized efficiently as a resource but treated as waste. These discarded shells are generally stacked or burned, which not only wastes resources but also pollutes the ecological environment [3].

With the prevalence of biomass utilization and the development of new and highly efficient agroforestry concepts, the use of agricultural and forestry waste as the matrix has become a research hotspot. The studied wastes can be pruned branch, fallen leaves, the by-products of fruit processing, and other types of plants residue. The common research topics include the liquefaction and application of liquidized waste (starch substitute in the surface sizing agent in papermaking) [8] [9], industrial production of tar, coke, and emulsion by hot cracking [7] [10], extraction of useful ingredients (tannin, polysaccharide, pigment, etc.) [6] [11], waste compost [12] [13], and manufacture of activated charcoal and biological adsorbents by using waste as raw materials [14]. Indeed, many of the processes have been widely used in the practical applications.

However, there are few studies on composting of Camellia oleifera Abel shells, Castanea mollissima Blume shells, or Carya cathayensis Sarg shells. Composting is a biological and chemical process to convert degradable organic matter into stable humus, which is a kind of continuous and efficient organic waste treatment technology. Moreover, it can effectively alleviate the environmental pressure, enhance soil fertility, and improve soil properties. In the meantime, this process also can alleviate the occurrence of diseases and insect pests to a certain extent [12]. Maturity indices are important standards to estimate the quality of compost products, which means organic matter in the compost is mineralized and finally stabilized. Over-maturity means a large number of nutrients in the waste are wasted, whereas the composting products with less-maturity can cause the decrease of the oxygen content in the soil, in which the harmful substances such as organic acids and $\mathrm{H}_{2} \mathrm{~S}$ have a negative effect on the normal growth of the plants [15]. Frequently-used maturity indices include temperature, $\mathrm{pH}, \mathrm{C} / \mathrm{N}$ and nitrogen composition, but these indices suffer from some significant limitations, 
such as narrow adaptation range, complex detection process, long cycle time, high cost, and challenging in quantification and factory scale composting. Thermal analysis is an effective means to study the thermodynamics and dynamics of various subjects. It can track all kinds of physical and chemical changes in the process of material heating. In particular, thermal analysis is often used to study wood [16]. Bernal [17] used the method of thermogravimetric analysis to analyze the change of compost in the composting experiment of wheat straw as the main raw material and found that the weight loss of the heap at $360^{\circ} \mathrm{C}-540^{\circ} \mathrm{C}$ exhibited a good correlation with the maturity, but no specific quantitative index was given. The three kinds of nutshells also contain a large number of wood fibers and polysaccharides. These substances will change significantly during the composting process, and these changes can be detected by the thermogravimetric analysis.

Infrared spectroscopy can identify the characteristic functional groups of the compounds and elucidate the structural changes of the materials. Their measurement needs less sample size, less destructive, simple testing, strong timeliness, and has a good potential for the monitoring of waste compost. In the analysis of municipal solid waste and sludge composting process by infrared spectroscopy, it was found that the variation of spectral characteristics was consistent with the change trend of the heap temperature and the seed germination index GI, which could reflect the change of organic components well and could be used as an index for judging the maturity [18] [19]. However, the conversion of organic components varies under different composting conditions [15].

In this paper, three kinds of shells materials are studied and analyzed by FTIR and thermogravimetric analysis. The composition and pyrolysis characteristics of the fruit shell are determined, which can provide a reference for the further application of three kinds of fruit shells.

\section{Experimental Materials and Methods}

\subsection{Materials}

Camellia oleifera Abel shells were obtained from Dongfanghong Forest Farm, Jinhua City, Zhejiang Province, China.

Carya cathayensis Sarg shells (Carya cathayensis Sarg) were acquired from Lin'an District, Hangzhou City, Zhejiang Province, China.

Castanea mollissima Blume shells (Castanea mollissima BL) were from Qingyuan County, Lishui City, Zhejiang Province.

All the three kinds of shells were collected in October 2017 and separated from fruit just by sheller (shelling by physical means) without any other treatment and exposed under the sunlight for removing excess water.

Then the shells were placed in an oven (DHG-9076A) at $105^{\circ} \mathrm{C}$ until the weight reached constant. A broken machine (DFT-40) was used to crush the dried shells into powder. Then the powder was sifted through an 80-mesh sieve (GB6003-88) and finally stored in a desiccator as a sample for use. 


\subsection{Analysis Method}

\subsubsection{Chemical Composition Analysis}

The chemical composition of the shells was determined according to the procedure of Liao [7]. The contents of lignin were determined by method regulated in Chinese National Standard GB/T 2677.8-1994 [20]. The contents of holocellulose were determined with the method of the national standard GB/T 2677.10-1995 [21]. The contents of cellulose were assayed by nitric acid-ethanol method [22]. A method based on GB/T 742-2008 was used to determine the contents of ash [23]. The content of hemicellulose was equal to the difference between the contents of holocellulose and cellulose. Each sample was analyzed three times for calculating the average percentage of the main components.

\subsubsection{Fourier Transform Infrared (FT-IR) Spectroscopy Analysis}

Fourier Transform Infrared Spectrometer (FTIR, Nicolet iS50, Thermo Fisher Scientific, USA) was used for the identification of various functional groups of the three shells. Oven-dried sample powder $0.001 \mathrm{~g}\left(105^{\circ} \mathrm{C}\right.$ for $\left.1 \mathrm{~h}\right)$ mixed with $0.1 \mathrm{~g} \mathrm{KBr}$ powder was pressed into the thin and transparent disk by pressed-disk technique and put into FTIR Spectrometer for one test. For each spectrum, a 32 -scan absorption interferogram was collected with a resolution of $4 \mathrm{~cm}^{-1}$ in the $400-4000 \mathrm{~cm}^{-1}$ region at ambient temperature. Analysis of each sample was repeated three times. The position and peak height of absorption peaks in infrared absorption spectrum were measured by origin 8.0.

\subsubsection{Thermogravimetric Analysis}

An SDT Q600 (TA Instruments) simultaneous thermal analyzer was used for the analysis of weight loss of the three shells. The experimentation settings were as follows: shells powder samples passed through 80 - to 100 -mesh sieves, $8 \mathrm{mg}$ in weight, heating rate at $10^{\circ} \mathrm{C} / \mathrm{min}, 99.99 \%$ nitrogen atmosphere with a flow rate of $50 \mathrm{~mL} / \mathrm{min}$, the initial temperature of $30^{\circ} \mathrm{C}$, and termination temperature of $800^{\circ} \mathrm{C}$ [24]. TA analysis and origin 8.0 were used to obtain thermogravimetric curve (TG curve, the relationship between mass and temperature under the programmed temperature) and derivative thermogravimetric curve (DTG curve, obtained by differentially obtaining the thermogravimetric curve and reflected the relationship between the change of sample quality and temperature/time). In the DTG curve, the lowest point on both sides of the absorption peak in the thermogravimetric curve is the cut-off point of the temperature at each stage.

\subsubsection{X-Ray Diffraction Analysis}

The 80-meshed nutshells powder was dried at the $50^{\circ} \mathrm{C}$ oven for $6 \mathrm{~h}$ and sheeted into thin slices at room temperature, followed by the measurement using a $\mathrm{Ri}$ gaku D/max 2550 PC type X-ray diffractometer. Experimental conditions were as follows: the $\mathrm{X}$-ray tube was a $\mathrm{Cu}$-target, and the $\mathrm{CuK} \beta$ radiation was eliminated with a nickel sheet with a tube voltage of $40 \mathrm{kV}$ and a tube current of $40 \mathrm{~mA}$. The measurement method was a $2 \theta / \theta$ linkage scan. The X-ray crystallinity index was calculated as Equation (1) [25]: 


$$
\mathrm{C}_{\mathrm{r}} \mathrm{I}=\frac{I_{002}-I_{\mathrm{am}}}{I_{002}} \times 100 \%
$$

In the formula, $\mathrm{C}_{\mathrm{r}} \mathrm{I}$ refers to the relative crystallinity (\%); $I_{002}$ is (002) lattice diffraction maximum intensity angle; $I_{\mathrm{am}}$ represents the scattering intensity of the $2 \theta$ angle near the amorphous background diffraction; and $I_{\mathrm{am}}$ is the same as the $I_{002}$ unit.

\section{Results and Discussion}

\subsection{Main Components and Contents of Three Kinds of Shells}

The contents of cellulose, hemicellulose, and lignin in the three kinds of shells are the material basis for their matrix utilization. The matrix utilization of three kinds of shells mainly depends on the degradation by microorganisms. From the aspect of biodegradation, hemicellulose is the most easily decomposable material, cellulose is a hardly decomposable material, and lignin is an anti-decomposition material [26]. According to methods in 2.2.1, the content of hemicellulose in the Camellia oleifera Abel shells was the highest of $49.34 \%$, followed by $33.23 \%$ of the Castanea mollissima Blume shells, whereas the lignin content in the Castanea mollissima Blume shells was the highest of $49.78 \%$ (Table 1). From these results, it can be concluded that the Camellia oleifera Abel shells and the Castanea mollissima Blume shells are relatively optimal substrates for matrix utilization.

\subsection{Infrared Spectrum Analysis of Three Kinds of Nutshells}

The type and number of chemical bonds can be inferred from the infrared spectral peak assignments of the three shells [27]. As Figure 2 shows, the infrared spectroscopy characterization of absorption peaks was similar among the three shells, for all absorption peaks corresponding to general cellulose, hemicellulose,

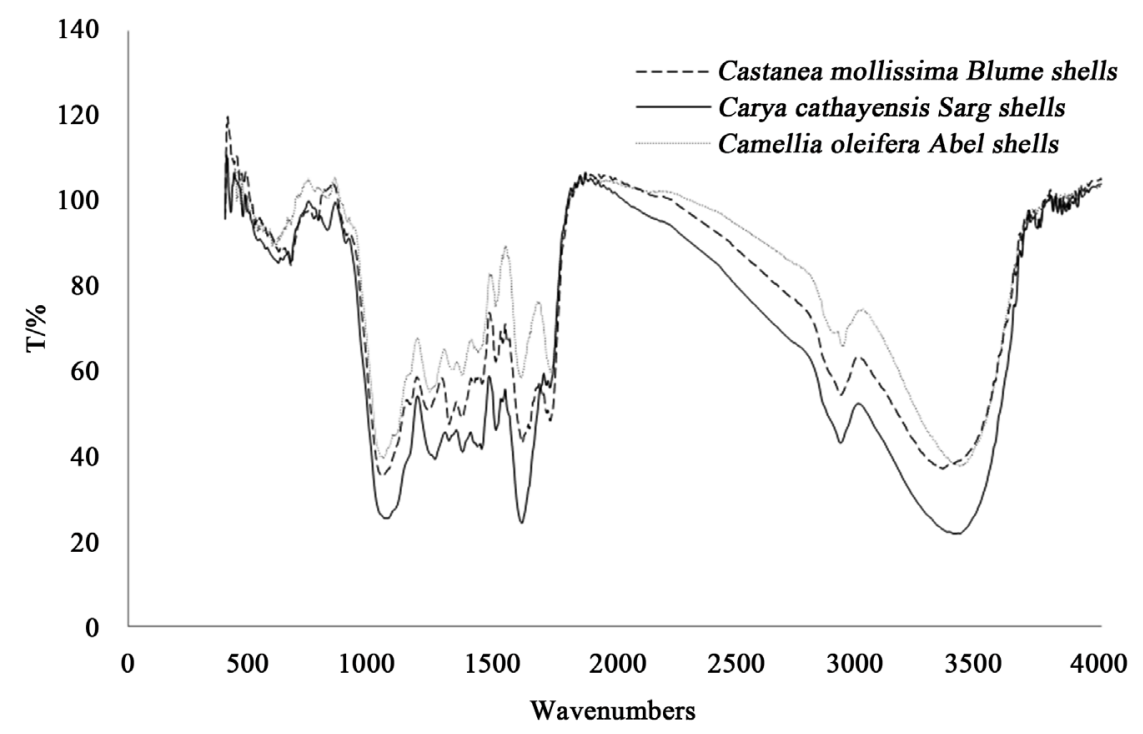

Figure 2. Infrared spectra of three shells. 
Table 1. Main ingredient content of three kinds of shells (\%).

\begin{tabular}{cccccc}
\hline species & cellulose & hemicellulose & lignin & ash & crystallinity \\
\hline Camellia oleifera Abel shells & $18.62 \pm 0.22$ & $49.34 \pm 0.07$ & $29.71 \pm 0.14$ & $2.57 \pm 0.04$ & 39.1 \\
Carya cathayensis Sarg shells & $20.63 \pm 0.07$ & $22.48 \pm 0.02$ & $49.78 \pm 0.01$ & $6.88 \pm 0.02$ & 64.4 \\
Castanea mollissima Bl. shells & $27.34 \pm 0.01$ & $33.23 \pm 0.02$ & $21.40 \pm 0.12$ & $3.22 \pm 0.01$ & 46.4 \\
\hline
\end{tabular}

and lignin. The peak at $3420 \mathrm{~cm}^{-1}$ corresponded to the hydroxyls of cellulose, hemicellulose, lignin, and water molecules. The absorption peaks at $2927 \mathrm{~cm}^{-1}$, $1452 \mathrm{~cm}^{-1}$, and $1374 \mathrm{~cm}^{-1}$ were the characteristic absorption peaks of cellulose, and the peaks at $1615 \mathrm{~cm}^{-1}, 1508 \mathrm{~cm}^{-1}$, and $1437 \mathrm{~cm}^{-1}$ were mainly attributed to the vibration of benzene ring skeleton, which can confirm the existence of lignin. The absorption peak near $1050.46 \mathrm{~cm}^{-1}$ was intensive, which corresponds to stretching vibration of C-O bond and alkoxy bond extension in acetyl in cellulose and hemicellulose. The absorption peak near $1734 \mathrm{~cm}^{-1}$ caused by the $\mathrm{C}-\mathrm{O}$ bond of the acetyl group and carboxyl group was a characteristic absorption peak of hemicellulose that is distinguished from other components [12] [16] [28] [29] [30].

It was known from the above spectral analysis that the main components of the three kinds of shells are cellulose, hemicellulose, lignin, and other minor components such as protein and polysaccharide. The location of absorption peaks is related to the type and structure of the substance while the intensity of absorption peak (expressed at the height of the peak) depends on the content of the components in the sample. These components undergo regular changes with the composting process and new substances were produced, which leads to the location and intensity of absorption peaks change as well [29]. Therefore, the location and intensity of absorption peaks can be used as an index for judging the maturity in the composting process [31]. It has been reported that the determination of the content of cellulosic substances by the infrared spectroscopy internal standard method can facilitate the understanding of the changes of the cellulose substances in the composting process and improvement of the composting process, which can probably solve the issue that the thickness of disks significantly affects the intensity of absorption peaks [32] [33]. Moreover, the time required by the infrared spectra analysis is often within two days, which is much shorter than other methods of determining chemical composition, thus tracking the material changes in composting process efficiently and solving the problems in composting process in time.

\subsection{Thermogravimetric Analysis}

It can be seen from the TG curve in Figure 3 that the three shells pyrolysis processes exhibited similarities and differences, which are roughly divided into three stages, namely dehydration, rapid weight loss, and slow weight loss stages. The initial temperature of each stage is shown in Table 2. In the first stage, the loss of weight mainly included the loss of free water, crystal water, and adsorbed 


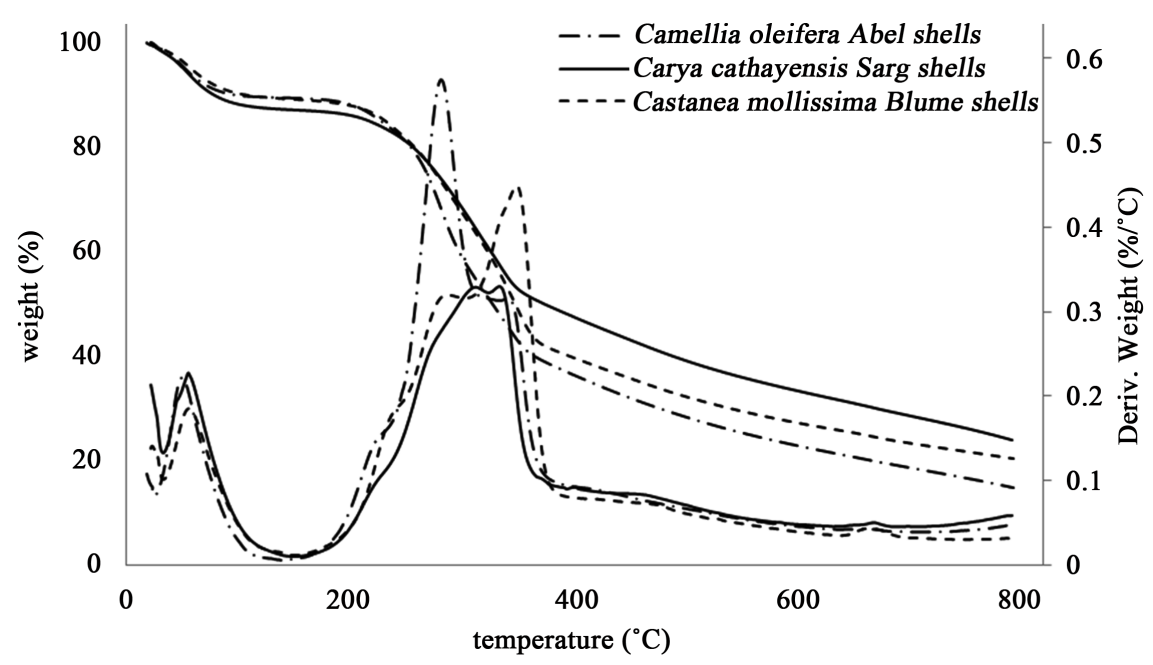

Figure 3. TG curves and DTG curves of three shells.

Table 2. Three-stage initial temperature table for three kinds of shells pyrolysis.

\begin{tabular}{cccc}
\hline Entry ${ }^{\circ} \mathrm{C}$ & First stage & Second stage & Third stage \\
\hline Camellia oleifera Abel shells & $25-136$ & $142-580$ & $>580$ \\
Carya cathayensis Sarg shells & $33.5-150$ & $150-395$ & $>394$ \\
Castanea mollissima Blume shells & $26-150$ & $150-410$ & $>410$ \\
\hline
\end{tabular}

water, as well as the release of small molecules such as terpenes [34] [35]. Dehydration stage of Camellia oleifera Abel shells occurred at $25^{\circ} \mathrm{C}-136^{\circ} \mathrm{C}$ with weight loss rate of $9.82 \%$ and weight loss peak temperature of $50.21^{\circ} \mathrm{C}$; this stage of Carya cathayensis Sarg shells occurred at $33.5^{\circ} \mathrm{C}-150^{\circ} \mathrm{C}$ with a weight loss rate of $10.87 \%$ and weight loss peak temperature of $55.87^{\circ} \mathrm{C}$; Carya cathayensis Sarg shells at $26^{\circ} \mathrm{C}-150^{\circ} \mathrm{C}$ with a weight loss rate of $10.28 \%$ and weight loss peak temperature of $55.52^{\circ} \mathrm{C}$ (Table 3). The weight loss wave of the first stage of Camellia oleifera Abel shells was $5.31^{\circ} \mathrm{C}-5.66^{\circ} \mathrm{C}$ lower than those of the other two shells, which means the shells lost moisture easier. It may be related to the low cellulose content, cellulose crystallinity and the high content of hemicellulose of Camellia oleifera Abel shells.

As the temperature continued to rise, the pyrolysis came into the second stage of obvious weight loss. The stage of Camellia oleifera Abel shells, Carya cathayensis Sarg shells, and Castanea mollissima Blume shells respectively occurred between $142^{\circ} \mathrm{C}-580^{\circ} \mathrm{C}, 150^{\circ} \mathrm{C}-395^{\circ} \mathrm{C}$, and $150^{\circ} \mathrm{C}-410^{\circ} \mathrm{C}$, with weight loss rates of $69.59 \%, 39.13 \%$, and $50.29 \%$. The weight loss peak temperatures of Camellia oleifera Abel shells, Carya cathayensis Sarg shells, and Castanea mollissima Blume shells were at $282^{\circ} \mathrm{C}$ and $341.81^{\circ} \mathrm{C}, 313.07^{\circ} \mathrm{C}$ and $334.16^{\circ} \mathrm{C}$, and $287.02^{\circ} \mathrm{C}$ and $348^{\circ} \mathrm{C}$, respectively (Table 3 ). At this pyrolysis stage, most of the hemicellulose, part of cellulose and lignin take place pyrolysis reactions, and volatile materials are generated that are then carried away by the nitrogen gas flow, which leads to a rapid decline in the TG curve [36]. At this stage, some glycosidic 
Table 3. Pyrolysis peak temperatures for three kinds of shells.

\begin{tabular}{cccc}
\hline Entry $/{ }^{\circ} \mathrm{C}$ & $\begin{array}{c}\text { C. oleifera } \\
\text { Abel shells }\end{array}$ & $\begin{array}{c}\text { C. cathayensis } \\
\text { Sarg shells }\end{array}$ & $\begin{array}{c}\text { C. mollissima } \\
\text { Blume shells }\end{array}$ \\
\hline Weight loss peak in dehydration stage & 50.21 & 55.87 & 55.52 \\
Left pyrolysis weight loss peak & 282.00 & 313.07 & 287.02 \\
Maximum weight loss peak temperature & 341.81 & 334.16 & 348.00 \\
\hline
\end{tabular}

Remark: C. oleifera Abel shells (Camellia oleifera Abel shells); C. cathayensis Sarg shells (Carya cathayensis Sarg shells); C. mollissima Blume shells (Castanea mollissima Blume shells).

bonds of hemicellulose, cellulose, and lignin in the shells start to break. Simultaneously, some $\mathrm{C}-\mathrm{O}$ and $\mathrm{C}-\mathrm{C}$ bonds start to break and produce new products and low molecular weight volatile compounds [37] [38]. Since the pyrolysis of hemicellulose occurs mainly at $200^{\circ} \mathrm{C}-300^{\circ} \mathrm{C}$ [39], the weight loss peaks on the left side of the weight loss wave are primarily attributed to the pyrolysis of polymers led by hemicellulose [40] [41], which is consistent with result that the weight loss of the three shells is directly proportional to the hemicellulose content. Since cellulose exhibited an inconspicuous peak at $330^{\circ} \mathrm{C}$ in TG analysis [42] the right side of weight loss peak is mainly caused by the pyrolysis and volatilization of cellulose-led polymers in the raw material [7] [25]. Lignin exhibited an inconspicuous peak at $350^{\circ} \mathrm{C}-420^{\circ} \mathrm{C}$ in TG analysis [41]. The degradation temperature of lignin was between $200^{\circ} \mathrm{C}$ and $500^{\circ} \mathrm{C}$, falling into the entire main pyrolysis stage [43] [44]. In the third stage, the TG curve varied slowly, and the weight loss was relatively slow, which is primarily due to the further degradation of some residual lignin and charcoal [45] [46].

Since the contents of the three major components of the shells are different, their shapes, temperatures, and numbers of weight loss peak vary quite significantly in the second stage. It can be seen from Figure 3 that the left side of weight loss peak of Camellia oleifera Abel shells exhibited an independent apex, whereas the right peak was not obvious. The left peak was significantly higher than the right weight loss peaks of other two raw materials. Castanea mollissima Blume shells showed a sharp and inconspicuous peak on the right side while the left side peak was not obvious. The weight loss peak on the right side was significantly higher than that on the left side, which also higher than the right peaks of the other two shells. The weight loss peaks on both left and right sides of the Carya cathayensis Sarg shells during this stage were not obvious. The peak temperature corresponding to Camellia oleifera Abel shells pyrolysis was the lowest, while the peak temperature on the weight loss of Carya cathayensis Sarg shells pyrolysis was the highest. After $400^{\circ} \mathrm{C}$, the weight loss trend of all raw materials tended to slow, which is the carbonization stage. At this stage, the pyrolysis of hemicellulose and cellulose is almost finished, and the pyrolysis of the $\mathrm{C}=\mathrm{C}$ bonds between the benzene ring structures is also basically completed, as well as the side chain of the benzene ring structure in the lignin molecule. However, 
since the benzene ring structure of the lignin molecule is relatively hard to decompose, pyrolysis of it forms more fixed carbon. Therefore, the TG and DTG curves tend to be flat [15].

Table 1 and Figure 2 show that the content of hemicellulose in Camellia oleifera Abel shells was $49.34 \%$, higher than the content combined of cellulose and lignin. The content of cellulose only accounts for $18.62 \%$, which is significantly lower than that of hemicellulose. Therefore, the left peak caused by the pyrolysis of hemicellulose and lignin obviously exists, but the right weight loss peak caused by the co-pyrolysis of cellulose and lignin is not obvious and is slightly shoulder-shaped. The content of hemicellulose in the Castanea mollissima Blume shells was $33.23 \%$, and the content of cellulose was $27.34 \%$ that was the highest among these three shells with a cellulose crystallinity of $46.4 \%$. As a result, the left side peak was not obvious, whereas the right side of weight loss peak caused by the pyrolysis of cellulose and lignin clearly exists. The lignin content of Castanea mollissima Blume shells was as high as $49.78 \%$, which is much higher than the lignin contents of the other two raw materials. The cellulose crystallinity was also the highest of $64.4 \%$ among the three raw materials while the hemicellulose content was only $22.48 \%$. Therefore, the left peak caused by the pyrolysis of hemicellulose is inconspicuous, and the temperature at which the peak appears is significantly higher than the temperatures at the left peaks of the other two raw materials. In the meantime, due to the high degree of crystallinity of cellulose, the right peak caused by the degradation of cellulose and lignin is also not obvious [30]. Therefore, it can be concluded that the different materials have different weight loss rates and weight loss peaks because of different physical structures and chemical compositions. For a chemical composition, the higher its content, the earlier its weight loss peak appears and the longer the duration of the peak. Since the three TG-DTG curves of the three shells can well reflect different contents and components of the three shells, the curves can also reflect the changes of components in the shells [47]. With the changes of raw material in composting process, the onset and duration of weight loss peaks will also change. These changes can reflect the degree of the composting. By using the thermogravimetric analysis, the weight loss rate and the time of the weight loss peak can be used as one of the indices to judge the degree of maturity. It may also be possible to identify a period of slow degradation during composting, which will facilitate the improvement of the composting process and quality.

\section{Conclusions}

Up to now, there is no clear standard for judgment of compost maturity. Infrared spectroscopy and themogravimety are easy to operate, with strong timeliness and accuracy, and they can directly reflect the changes of substance in composting. Sun [29] and Bernal [17] have mentioned these two methods, but due to the complexity of composting materials and conditions, these two methods do not have quantitative indicators. In the article, three kinds of shells were analysised 
by infrared spectroscopy and themogravimety for verifying the practicability and feasibility of the two methods. The following conclusions can be drawn from the experiment:

1) From the infrared spectra of the three kinds of shells, it can be concluded that the three main components of the shells are cellulose, hemicellulose, and lignin. There are differences in the content of each component. The content of cellulose from high to low is Castanea mollissima Blume shells, Carya cathayensis Sarg shells, and Camellia oleifera Abel shells. The highest content of hemicellulose in the three shells is Camellia oleifera Abel shells, followed by Castanea mollissima Blume shells, and Carya cathayensis Sarg shells. The content of lignin is in the order of Carya cathayensis Sarg shells, Camellia oleifera Abel shells, and Castanea mollissima Blume shells. The variation in the FTIR of the three components during the composting process can reflect the change of material components and content in each stage, which can help to understand the specific change process of the material during the composting process and solve the problems in the process of composting quickly and effectively.

2) The pyrolysis process of three kinds of shells consists of three stages, namely dehydration, pyrolysis, and carbonization stages. The first stage is the loss of crystal water in the temperature range of $25^{\circ} \mathrm{C}-150^{\circ} \mathrm{C}$ with a maximum water loss rate at about $55^{\circ} \mathrm{C}$. The second stage is the pyrolysis process of woody fiber, which is the main component of the shells. The starting temperature of hemicellulose pyrolysis is the lowest with maximum weight loss peak at $290^{\circ} \mathrm{C}$ $310^{\circ} \mathrm{C}$. The pyrolysis temperatures of cellulose and lignin are relatively high, whose maximum weight loss peak at around $340^{\circ} \mathrm{C}$. Due to the difference in the contents of the three major components, there are differences in the temperature and shape of the weight loss peaks. The weight loss peak temperature of the three kinds of shells is proportional to the content of each component and cellulose crystallinity. Lower content and higher crystallinity make the peak appear at a higher temperature. And the residual carbon ratio of the Carya cathayensis Sarg shells was the highest (23.98\%), followed by the Carya cathayensis Sarg shells (20.33\%), and the lowest residual carbon content was the Camellia oleifera Abel shells (14.86\%). The lignin content of the Carya cathayensis Sarg shells was the highest among the three kinds of shells, and the content of Camellia oleifera Abel shells was the lowest. By the results of this study, the results of thermogravimetric analysis of different components have a direct visual difference, which directly reflects the difference in the material content, and the process of compost is also a process of material change. Thermogravimetric analysis can be used to identify the change of the material content during the composting process.

3) Thermogravimetry can reflect the change of material content in the process of composting, while infrared spectroscopy can be used for detection accurately. So TG-FTIR can be used to accurately determine the change of materials in the process of composting. 


\section{Acknowledgements}

The authors are grateful for the financial support from Provincial Department of Science and Technology of Zhejiang, China, Grant No.2017C02022.

\section{Conflicts of Interest}

The authors declare no conflicts of interest regarding the publication of this paper.

\section{References}

[1] Li, Z.J. (1981) Camellia oleifera. China Agriculture Press.

[2] Yang, Z.B., Yang, L. and Xu, X.Y. (2007) Prospect on Utilization of Current Status and Residual for Castanea mollissima. Hubei Forestry Science \& Technology, 1, 57-59.

[3] Xiang, Y.Z. (2013) Study on Agricultural Substrate Development and Application of Hickory Hull. China Academy of Forestry.

[4] Zero Power Intelligence Group (2017) Annual Research and Consultation Report of Panorama Survey and Development Strategy on China Industry.

http://www.chinairn.com.cn/

[5] Jiang, Z.F., Lin, M., Li, X. and Bai, X.P. (2018) Research Progress on Main Extracts of Camellia oleifera and Their Bioactivities. Journal of Hainan Normal University: Natural Science Edition, 31, 55-59.

[6] Li, L.M. (2013) Study on the Active Substances from Eight Kinds of Camellia oleifera Extract and Their Antioxidant Activities. Doctoral Dissertation, Zhejiang University, Hangzhou.

[7] Liao, Y.Y. (2016) Pyrolysis of Fruit Shell Biomass and Its Products. Doctoral Dissertation, Central South University of Forestry and Technology, Changsha.

[8] Yao, X.O. (2016) Liquefaction and Application of Camellia Processing Residues. Doctoral Dissertation, Fujian Normal University, Fuzhou.

[9] Hong, C.D., Weng, J.Z. and Wu, Z.H. (2017) Cationic Modification and Surface Sizing Properties of Liquefied Oil Tea Cake. China Paper Industry, 38, 40-43.

[10] Lin, J. (2015) Biorefining Technology for Processing Residues of Camellia oleifera. Doctoral Dissertation, Fujian Normal University, Fuzhou.

[11] Zhang, S. (2013) Extraction, Activity and Application of Polysaccharides from Common Camellia Cake and Husk. Doctoral Dissertation, Central South University of Forestry and Technology, Fuzhou.

[12] Zhang, L. (2015) Process Control and Product Improvement and Application of Gardening Waste Composting. Doctoral Dissertation, Beijing Forestry University, Beijing.

[13] Sun, X.Y., Solina, Xu, J. and Du, J.J. (2012) Status and Policy of Landscaping Waste Disposal. Garden, 2, 12-17.

[14] Yu, S.Y. (2010) Preparation of Activated Carbon from Camellia oleifera Shell and Its Adsorption for Phenol. Application Chemistry, 39, 823-826.

[15] Zhang, Y.N. (2004) Establishment of Indicators and Methods for Rapid Determination of Compost Maturity. Doctoral Dissertation, China Agricultural University, Beijing.

[16] Li, J. (2003) Wood Spectroscopy. Science Press. 
[17] Bernal, M.P., Sanchezmonedero, M.A., Paredes, C. and Roig, A. (1998) Carbon Mineralization from Organic Wastes at Different Composting Stages during Their Incubation with Soil. Agriculture Ecosystems \& Environment, 69, 175-189. https://doi.org/10.1016/S0167-8809(98)00106-6

[18] Chefetz, B., Hatcher, P.G., Hadar, Y. and Chen, Y. (1996) Chemical and Biological Characterization of Organic Matter during Composting of Municipal Solid Waste. Journal of Environmental Quality, 25, 776-785. https://doi.org/10.2134/jeq1996.00472425002500040018x

[19] Kang, J., Zhang, Z.Q., Shao, M. and Wang, B. (2010) Relationship of Spectroscopic Characteristics of Humin Acid and Compost Maturity during Composting of Sewage Sludge. Acta Agriculturae Boreali-occidentalis Sinica, 19, 181-185.

[20] National Standardization Technical Committee 141 on Paper Industry of Standardization Administration of China (1995) GB/T2677.8-1994 Determination of Acid-Insoluble Ligin Content in Papermaking Raw Materials. Chinese Standard Press, Beijing.

[21] National Standardization Technical Committee 141 on Paper Industry of Standardization Administration of China (1996) GB/T2677.10-1995 Determination of Holocellulose Content in Papermaking Raw Materials. Chinese Standard Press, Beijing.

[22] Wang, L.F. and Cheng, Y.C. (2011) Determination the Content of Cellulose by Nitric Acid-Ethanol Method. Chemical Research, 22, 52-55.

[23] National Standardization Technical Committee 141 on Paper Industry of Standardization Administration of China (2008) GB/T 742-2008 Fiberous Raw Material Pulp Paper and Board-Determination of Ash. Chinese Standard Press, Beijing.

[24] Mishra, R.K. and Mohanty, K. (2017) Pyrolysis Kinetics and Thermal Behavior of Waste Sawdust Biomass Using Thermogravimetric Analysis. Bioresource Technology, 251, 63-74. https://doi.org/10.1016/j.biortech.2017.12.029

[25] Zhang, J., Wang, Z., Du, M., Yao, X. and Hu, L. (2014) Physicochemical Properties of Camellia Nut Shell and Its Thermal Degradation Characteristics. Bioresources, 10, 647-659. https://doi.org/10.15376/biores.10.1.647-659

[26] Kirk, T.K., Higuchi, T. and Chang, H.M. (2017) Lignin Biodegradation: Microbiology, Chemistry, and Potential Applications. Inorganic Organic Physical \& Analytical Chemistry, Vols. I and II.

[27] Jiang, J.X., Yang, Z.K., Zhu, L.W., Shi, L.M. and Yan, L.J. (2008) Structure and Property of Bamboo Fiber. Chinese Forestry Science and Technology, 30, 128-132.

[28] Yu, Z.X., Yang J.J., Wang, Y.Y., Zhang, L.G., Chang, J., Gao, H.J. and Sun, Y.D. (2016) Physical and Chemical Maturity Indexes and Fourier Transform Infrared (FTIR) Spectroscopy of Animal Manures during Composting. Chinese Journal of Applied Ecology, 27, 2015-2023.

[29] Xu, Y.K., Sun, X.Y., Luan, Y.N., Qu, P., Jiang, M.L., Zhang, L. and Li, W.Y. (2014) Infrared Spectral Analysis of Garden Waste Compost. Soil Bulletin, 45, 1071-1076.

[30] Gu, J., Liu, B., Zhang, Q.S., Chen, D.Y. and Zhou, J.B. (2015) Pyrolysis Characteristics Study of Camellia Shell and Its Three Main Components Based on TG-FTIR. China Forest Products Industry, 42, 9-13.

[31] Huang, G.Q., Han, L.J., Fan, X. and Yang, Z.L. (2006) Application Survey of Analytical Technique of Near Infrared Spectroscopy on Studies of Livestock Manure Compost. Journal of China Agricultural University, 11, 93-97.

[32] Fan, H.Q., Wang, X.M. and Wang, Y.M. (2014) Rapid Determination of Wood Cellulose Content by Fourier Transform Infrared Spectrometry. Wood Processing 
Machinery, 25, 33-37.

[33] Wu, S., Lou, H.M., Mo, X.K., Kong, H.H., Huang, Y.F., Wang, H. and Qiu, X.Q. (2014) Determination of Lignin in Tobacco by Mid-Infrared Spectroscopy. Tobacco Science \& Technology, 48, 58-62.

[34] Zhao, W.T., Chen, H.X., Zhou, J.J. and Liu, N.A. (2009) Characteristics and Kinetics of Forest Peat Pyrolysis. Acta Physico-Chimica Sinica, 25, 1756-1762.

[35] Ulloa, C.A., Gordon, A.L. and García, X.A. (2009) Thermogravimetric Study of Interactions in the Pyrolysis of Blends of Coal with Radiata Pine Sawdust. Fuel Processing Technology, 90, 583-590. https://doi.org/10.1016/j.fuproc.2008.12.015

[36] Yang, H., Yan, R., Chin, T., Liang, D., Chen, H. and Zheng, C. (2004) Thermogravimetric Analysis-Fourier Transform Infrared Analysis of Palm Oil Waste Pyrolysis. Energy \& Fuels, 18, 1814-1821. https://doi.org/10.1021/ef030193m

[37] Yin, C. (2012) Microwave-Assisted Pyrolysis of Biomass for Liquid Biofuels Production. Bioresource Technology, 120, 273. https://doi.org/10.1016/j.biortech.2012.06.016

[38] Huang, T., Jiang, J.M., Wang, J.L., Lian, W.W., Zhang, J. and Deng, Y.G. (2009) Study on Structure and Thermal Property of Pineapple Leaf Fiber. Shanghai Textile Science \& Technology, 37, 9-12.

[39] Dawy, M. and Nada, A.Â.M.A. (2003) IR and Dielectric Analysis of Cellulose and Its Derivatives. Journal of Macromolecular Science: Part D-Reviews in Polymer Processing, 42, 643-658. https://doi.org/10.1081/PPT-120023100

[40] Müller-Hagedorn, M., Bockhorn, H., Krebs, L. and Müller, U. (2003) A Comparative Kinetic Study on the Pyrolysis of Three Different Wood Species. Journal of Analytical \& Applied Pyrolysis, 68-69, 231-249. https://doi.org/10.1016/S0165-2370(03)00065-2

[41] Park, Y.H., Kim, J., Kim, S.S. and Park, Y.K. (2009) Pyrolysis Characteristics and Kinetics of Oak Trees Using Thermogravimetric Analyzer and Micro-Tubing Reactor. Bioresource Technology, 100, 400-405. https://doi.org/10.1016/j.biortech.2008.06.040

[42] Baldinger, T., Moobauer, J. and Sixta, H. (2000) Supermolecular Structure of Cellulosic Material by Fourier Transform Infrared Spectroscopy (FT-IR) Calibrated by WAXS and 13C NMR. Lenzing Berichte, 79, 15-17.

[43] Gang, W., Wen, L., Lia, B. and Chena, H. (2008) TG Study on Pyrolysis of Biomass and Its Three Components under Syngas. Fuel, 87, 552-558.

[44] Gaur, S. and Reed, T.B. (1995) An Atlas of Thermal Data for Biomass and Other Fuels. Office of Scientific \& Technical Information Technical Reports. https://doi.org/10.2172/82384

[45] Kim, S.S., Kim, J., Park, Y.H. and Park, Y.K. (2010) Pyrolysis Kinetics and Decomposition Characteristics of Pine Trees. Bioresource Technology, 101, 9797-802. https://doi.org/10.1016/j.biortech.2010.07.094

[46] Wang, M.F., Jiang, E.C. and Zhou, L. (2009) Kinetic Analysis of Cornstalk Pyrolysis. Transactions of the Chinese Society of Agricultural Engineering, 25, 204-207.

[47] Wu, C.F. (2007) Bailong Port Sludge High Temperature Aerobic Composting Maturity Index. Doctoral Dissertation, Tongji University. 